\title{
Therapeutic effects of antimicrobial treatment during lactation of recently acquired bovine subclinical mastitis: Two linked randomized field trials
}

\author{
B. H. P. van den Borne, ${ }^{* 1}$ G. van Schaik, † T. J. G. M. Lam,†‡ and M. Nielen* \\ ${ }^{*}$ Faculty of Veterinary Medicine, Utrecht University, Yalelaan 7, 3584 CL Utrecht, the Netherlands \\ †GD Animal Health Service, PO Box 9, 7400 AA Deventer, the Netherlands \\ ‡Dutch Udder Health Centre, PO Box 2030, 7420 AA Deventer, the Netherlands
}

\begin{abstract}
Two linked randomized field trials were performed on 39 herds in the Netherlands to 1) determine therapeutic effects of antimicrobial treatment of recently acquired subclinical mastitis (RASCM) during lactation, 2) evaluate the effect of duration of subclinical mastitis on therapeutic outcome, and 3) identify factors related to the therapeutic success of RASCM. Cows with a first elevated composite somatic cell count (CSCC) after 2 consecutive low CSCC measurements were eligible for enrollment in trial 1 (treatment at the first elevated CSCC). Quarter milk samples were collected to determine bacteriological status for major pathogens and coagulase-negative staphylococci. Cows with one or more culture-positive quarters with a quarter somatic cell count (QSCC) $\geq 100,000$ cells $/ \mathrm{mL}$ were defined to have RASCM and were randomly assigned treatment or control (no treatment). Untreated cows from trial 1 that had a second elevated CSCC at the next milk recording were eligible for enrollment in trial 2 (treatment at the second elevated CSCC). In trial 2, staphylococci-positive cows (Staphylococcus aureus and coagulase-negative staphylococci) were randomly assigned to treatment or control. Farmers used their own treatment protocols to treat quarters in both trials. Bacteriological cure was defined as absence of the pathogen identified pre-intervention in 2 samples post-intervention; QSCC, CSCC, and milk yield were also analyzed. Hierarchical logistic and linear models were used to determine therapeutic effects and to identify factors related to therapy outcome. Treated quarters had a higher bacteriological cure rate than control quarters for all pathogens in both trials. Treatment resulted in lower QSCC and CSCC, whereas milk yield was not affected by treatment. Bacteriological cure of RASCM was better in quarters with a low QSCC pre-intervention and in coagulase-negative staphylococci-positive quarters. Control quarters with
\end{abstract}

Received July 14, 2009.

Accepted October 9, 2009.

${ }^{1}$ Corresponding author: b.vandenborne@uu.nl a single culture-positive sample pre-intervention also had a higher bacteriological cure than control quarters with $\geq 2$ culture-positive samples. Time of antimicrobial treatment affected bacteriological cure for penicillinsensitive Staph. aureus. Bacteriological cure tended to be higher for Staph. aureus after treatment at the first elevated CSCC compared with treatment at the second elevated CSCC. Thus, early treatment of Staph. aureus might be more effective than later treatment.

Key words: subclinical mastitis, antimicrobial treatment, randomized clinical trial

\section{INTRODUCTION}

Subclinical mastitis (SCM) leads to decreased milk yield, increased probabilities of culling and clinical mastitis (Reksen et al., 2006, 2007), and an increased SCC. Additionally, SCM can be a source of infection for other cows because pathogens can be transmitted between cows (Lam et al., 1996; Zadoks et al., 2001).

Treating SCM with antimicrobials during lactation is one of the options to improve udder health in a dairy herd. Economic calculations using deterministic (Swinkels et al., 2005) and stochastic (Steeneveld et al., 2007) models have shown that antimicrobial treatment of SCM during lactation can be beneficial. Several clinical trials have been conducted to estimate efficacy of antibiotic treatment of SCM during lactation (Sol et al., 1997; McDougall, 1998; Wilson et al., 1999; St. Rose et al., 2003; Oliver et al., 2004; Deluyker et al., 2005; Salat et al., 2008; Sandgren et al., 2008). Pathogen and treatment factors, such as duration of treatment, pathogen species, and antimicrobial susceptibility affect bacteriological cure rates of SCM (Barkema et al., 2006). Additionally, several cow-level factors affected treatment success of chronic SCM. Parity, number of quarters infected, lactation stage, and location of affected quarter were associated with cure of Staphylococcus aureus SCM (Sol et al., 1997; Deluyker et al., 2005; Salat et al., 2008).

Early treatment of SCM is generally believed to improve therapeutic success (Barkema et al., 2006). 
Bacteriological cure seemed to be related to the length of infection in a pilot study on cows in early lactation (Beggs and Wraight, 2006) and in experimentally infused animals (Milner et al., 1997; Owens et al., 1997). Also, consecutive culture-positive samples were associated with reduced bacteriological cure of SCM after treatment in lactation (Sol et al., 1994) and at drying off (Sol et al., 1997; Dingwell et al., 2003). Repeated culturing of a pathogen is advocated to identify SCM pretreatment in field studies (Barkema et al., 2006). However, using consecutive samples to identify SCM is not regularly applied in dairy practice because it is expensive and impractical. Instead, composite somatic cell counts (CSCC) from the milk recording, in combination with a single bacteriological culture, are commonly used to identify SCM in dairy herds worldwide (Schukken et al., 2003). Changes in CSCC reflect new SCM cases and are of diagnostic value in identifying new SCM cases eligible for treatment, but have a low sensitivity (Dohoo and Leslie, 1991). Increasing the duration of elevated CSCC increases the diagnostic ability to identify SCM (Dohoo and Leslie, 1991) but will most likely decrease the probability of cure due to chronicity (Barkema et al., 2006). Thus, there is a need to evaluate the use of CSCC as a diagnostic tool to treat recently acquired subclinical mastitis (RASCM).

The objectives of this study were to 1 ) determine therapeutic effects of RASCM after antimicrobial treatment during lactation, 2) evaluate the effect of duration of SCM on therapeutic outcome, and 3) identify factors related to therapeutic success of RASCM.

\section{MATERIALS AND METHODS}

Two linked randomized, clustered clinical trials were conducted. Both trials were based on CSCC information from the milk recording to identify RASCM. The first trial randomly allocated antimicrobial treatment to staphylococci and streptococci RASCM identified after a first elevated CSCC. The second trial randomly allocated antimicrobial treatment to staphylococci SCM after the second elevated CSCC. The primary outcome analyzed was bacteriological cure at the quarter level. Quarter somatic cell count (QSCC), CSCC, and milk yield at the cow level were analyzed in both trials to evaluate practical relevancy.

\section{Herds}

The trials were performed from December 2006 through May 2008 in 40 Dutch dairy herds. Herds with a high number of new SCM cases were targeted. To be included, herds had to 1) participate in the DHI program at 4 -weekly intervals, 2) have more than 50 cows,
3) have an average incidence of first elevated CSCC of more than $10 \%$ in the milk recording in the year preceding the start of the trials, 4) milk without an automatic milking system, and 5) have reliable record-keeping capabilities. This information was checked in herd records and by contacting the farmers' veterinarians.

Herds were enrolled in December 2006 or January 2007, and data collection ended between October 2007 and May 2008, depending on the farm. In 3 herds, data collection was ceased in October 2007 because of the installation of an automatic milking system $(n=1)$ or because of an irregular interval of the DHI program (n $=2$ ). In 19 herds, the last cows were enrolled in January 2008, whereas in 17 herds with a high incidence of Staph. aureus SCM, the last cows were enrolled in March 2008 to obtain the required sample size for this pathogen.

Median bulk milk SCC of the participating herds was 231,000 cells $/ \mathrm{mL}$ in the month of enrollment and ranged from 123,000 to 365,000 cells/mL. Mean herd size was $87.5(\mathrm{SD}=37.1)$. Average herd-level 305-d milk production was $8,704 \mathrm{~kg}(\mathrm{SD}=894)$ and breed of cow was mainly Holstein-Friesian. All cows were milked twice daily and were housed in freestall barns with cubicles. In most herds $(31 / 39)$, cows were on pasture during summer (April/May to September/October). Udder cleaning was practiced before cluster attachment in all but one herd, and prestripping was carried out in 28 herds. Postmilking teat disinfection was carried out in 38 herds, and mastitic cows were milked last in 8 herds. All but 3 herds used blanket dry-cow treatment; in 3 herds an internal teat sealant was used in addition. In 2 herds selective dry-cow treatment was used. One herd farmed under organic conditions and cows were not dried off but milked continuously until the next calving. In this particular herd, some groups of cows were housed on straw bedding and teats of lactating cows were not disinfected after milking.

\section{Inclusion and Exclusion Criteria}

A multiparous cow was assumed to have RASCM during lactation (and thus was eligible for enrollment) when at the 4-weekly milk recording, CSCC was $\geq 250,000$ cells $/ \mathrm{mL}$ after 2 consecutive milk recordings $<250,000$ cells $/ \mathrm{mL}$. Multiparous cows with a CSCC $\geq 250,000$ cells $/ \mathrm{mL}$ in the first or second milk recording postpartum were also selected if, respectively, the last 2 or last milk recording before dry off were $<250,000$ cells/mL. For primiparous cows, a threshold of 150,000 cells/mL was used (after 2 consecutive milk recordings $<150,000$ cells $/ \mathrm{mL}$ ). Primiparous cows with a CSCC $\geq 150,000$ cells $/ \mathrm{mL}$ in the first or second milk recording postpartum were also selected. The CSCC measure- 
ments of samples collected within $72 \mathrm{~h}$ postpartum were disregarded. Thresholds for both primiparous and multiparous cows were chosen according to the Dutch DHI program to evaluate practical relevancy.

Cows were excluded from the study if they 1) had teat injuries, 2) received antimicrobial treatment in the last $30 \mathrm{~d}$ before enrollment, or 3) were expected to be culled or dried off in the next $60 \mathrm{~d}$. Cows enrolled only once, but could have more than 1 quarter infected with the same or with different pathogens at enrollment.

Cows were monitored by the farmer for clinical mastitis (i.e., clots in the milk) and other diseases for 4 wk after intervention. Enrolled quarters were clinically examined post-intervention. Enrolled cows that were withdrawn from the trials by the farmer (e.g., drying off, culling) were omitted from the study.

\section{Enrollment of Cows}

Cows that met the inclusion criteria were eligible for enrollment in trial 1: treatment at the first elevated CSCC (Figure 1). All lactating quarters were sampled within $10 \mathrm{~d}(\mathrm{~d}-7)$ after the milk recording, were analyzed for bacteriological status, and QSCC was determined. Regardless of bacteriological status, all quarters with QSCC $\geq 100,000$ cells $/ \mathrm{mL}$ were sampled again 1 wk later on d 0 (day of treatment). Quarters with QSCC $\geq 100,000$ cells $/ \mathrm{mL}$ and one of the following bacteria identified at d -7: Staph. aureus, Streptococcus uberis, Streptococcus dysgalactiae, Streptococcus agalactiae, Escherichia coli, other streptococci, or CNS were enrolled and were randomly allocated antimicrobial treatment or untreated control at the cow level at d 0 . If all tested quarters of a cow were culture negative at $d-7$ for the pathogens listed above, the cow was excluded from trial 1. However, this cow was sampled on all quarters with QSCC $\geq 100,000$ cells $/ \mathrm{mL}$ on d 0 to be eligible for enrollment in trial 2.

In trial 2, bacteriological culture-positive control cows from trial 1 and bacteriological culture-negative cows at $d-7$ from trial 1 were eligible for enrollment (Figure 2). All cows with a second elevated CSCC qualified for enrollment and were tested equally to trial 1 at $\mathrm{d}$ -7 . All quarters with QSCC $\geq 100,000$ cells $/ \mathrm{mL}$ were sampled again 1 wk later (d 0). Cows were randomly allocated to antimicrobial treatment at $\mathrm{d} 0$ in trial 2 if, in the same quarter, QSCC was $\geq 100,000$ cells $/ \mathrm{mL}$ and Staph. aureus or CNS was identified in one or more quarters. Cows with other pathogens identified were excluded from trial 2.

To determine bacteriological status post-intervention, all treated and control quarters in trials 1 and 2 were sampled twice at d 21 and 28 post-intervention. Follow- up of cows and quarters in both trials is shown in Figures 1 and 2 .

In the Netherlands, CNS is the most prevalent pathogen (Sampimon et al., 2009). It was therefore decided to randomly exclude half of the CNS-positive cows from both trials for equal distribution of included pathogens ( $\mathrm{n}=223$ and $\mathrm{n}=26$ for trial 1 and 2, respectively; Figures 1 and 2).

\section{Randomization}

Cows infected with staphylococci were randomized at both the first and second elevated CSCC, whereas cows infected with streptococci and E. coli were only randomized at the first elevated CSCC in a ratio of 1:1 for treatment and control. For staphylococci-positive cows, a ratio of 1:4 for treatment and control at the first randomization (trial 1) was used to meet the appropriate sample sizes in trial 2. A ratio of 1:1 for staphylococci-positive cows was used for treatment and control in trial 2.

During data collection, randomization ratios were adjusted 3 times to meet the appropriate pathogenspecific sample sizes. Randomization ratios changed in July 2007 for streptococci and E. coli and in October 2007 and February 2008 for Staph. aureus (Table 1).

Pathogen-specific blocks of cows within a herd were filled to minimize the effect of between-herd variability (e.g., different pathogen distribution, mastitis management, and treatment regimens). A dice was thrown to randomly allocate treatment to cows or to exclude them, in the case of CNS.

\section{Sample Size}

The primary outcome, bacteriological cure at the quarter level, was used to estimate the pathogen-specific sample sizes required for each trial. With $\alpha=0.05$ (1-tailed), $\beta=0.20$ and absolute differences in cure rates of $25 \%$ (Sol et al., 1997) and 35\% (St. Rose et al., 2003) for staphylococci and streptococci, respectively, 45 and 21 quarters were required per group. To have sufficient data available for analysis, the study was continued until sample sizes were reached at the cow level rather than the quarter level. In addition, absolute differences in cure rate were calculated, with the cure rate of treated quarters set at the proportion with the largest variance and sample size possible (50\%). For example, the cure rate of staphylococci was set at $50 \%$ for treated quarters and at $25 \%$ for control quarters. This increased the sample size somewhat to correct for incomplete data and for correlation within clusters (quarters within cows within herds). 


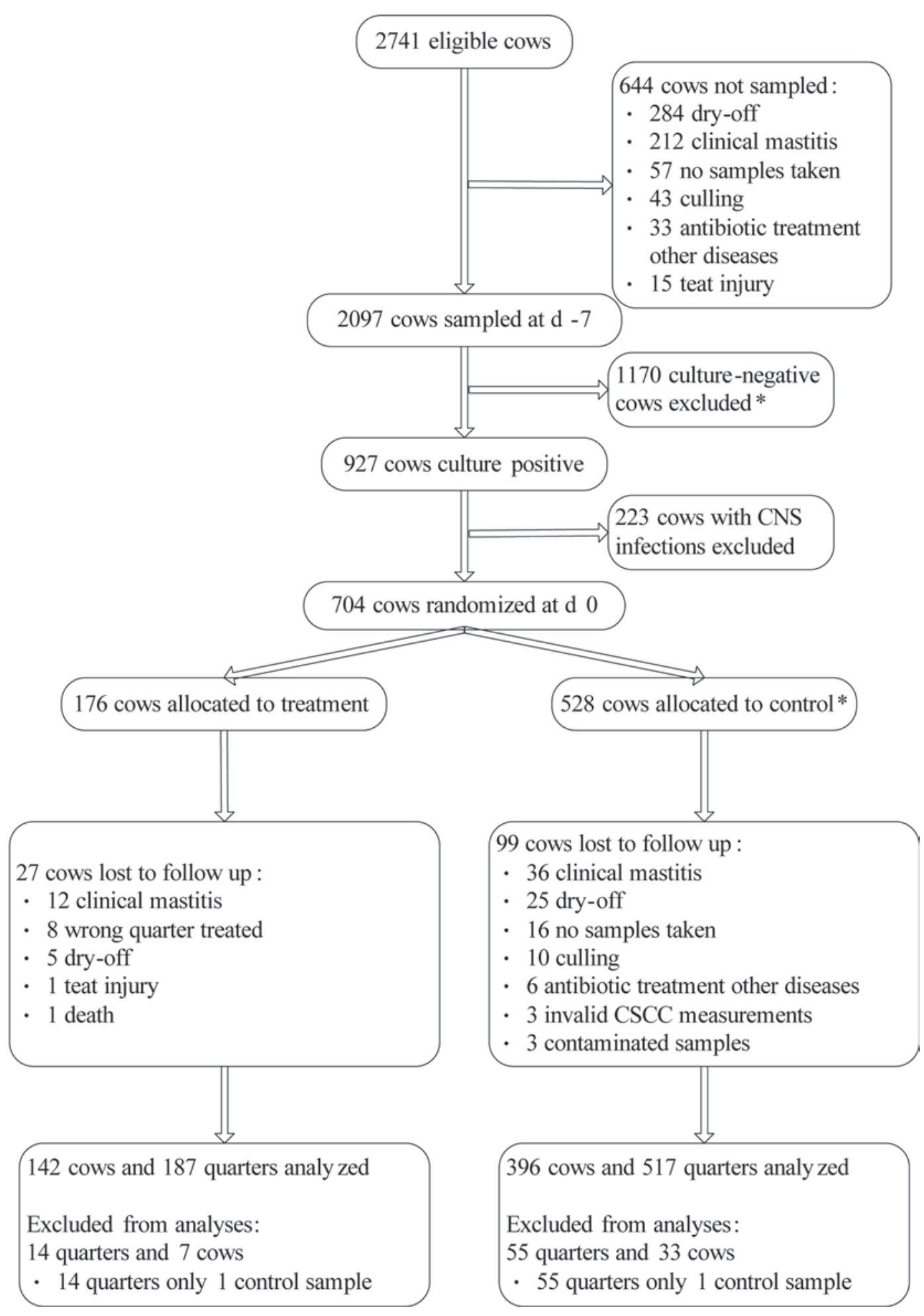

Figure 1. Flow diagram of cows and quarters through trial 1: treatment of subclinical mastitis at the first elevated composite SCC (CSCC). *Groups of cows indicated with asterisk were eligible for enrollment in trial 2. 


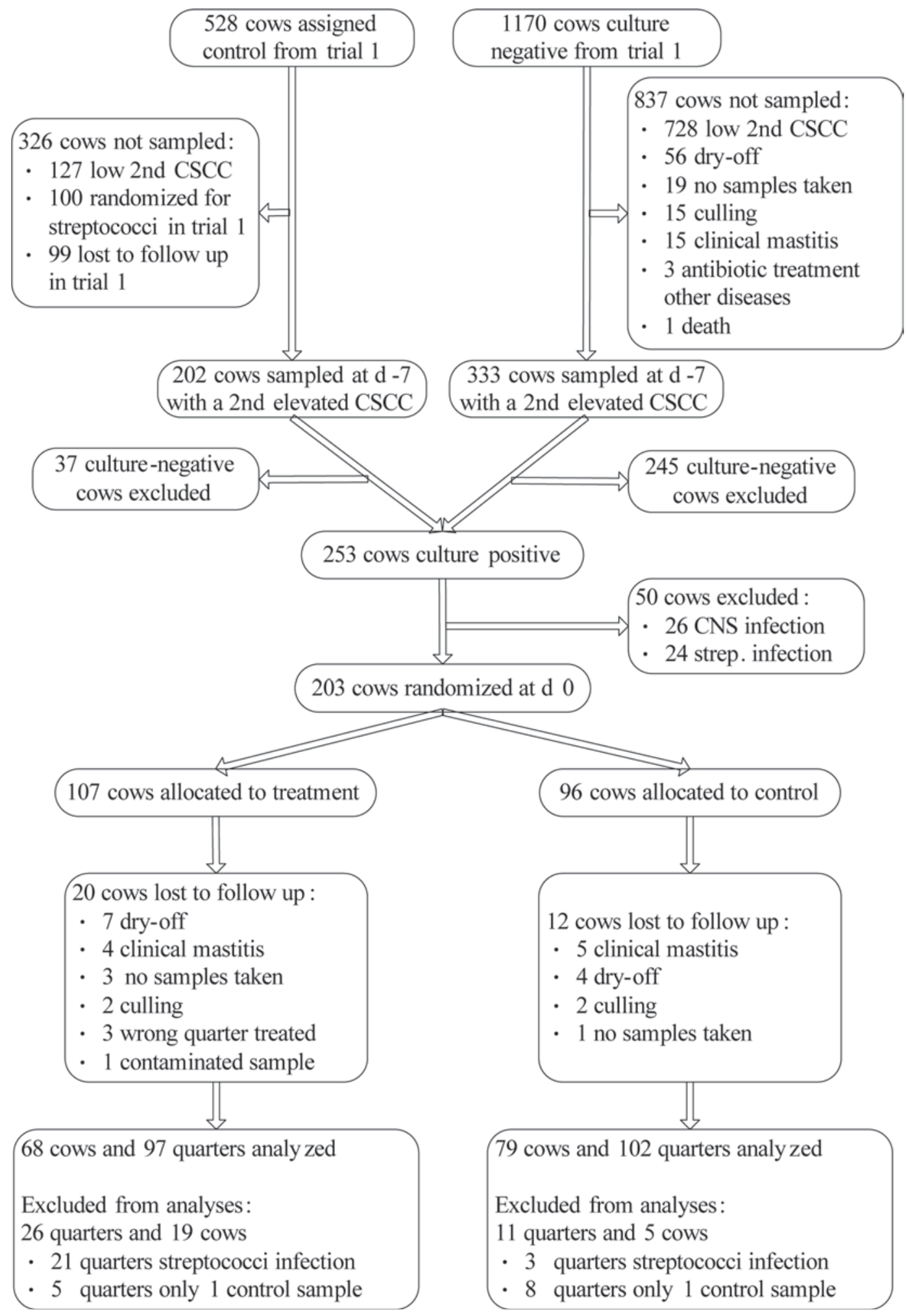

Figure 2. Flow diagram of cows and quarters through trial 2: treatment of staphylococci subclinical mastitis at the second elevated composite SCC (CSCC). 
Table 1. Percentage of quarters according to covariates used in the statistical analyses for bacteriological cure by trial and treatment group

\begin{tabular}{|c|c|c|c|c|c|}
\hline \multirow[b]{2}{*}{ Variable } & \multirow[b]{2}{*}{ Category } & \multicolumn{2}{|c|}{ Trial 1: first elevated CSCC $^{1}$} & \multicolumn{2}{|c|}{ Trial 2: second elevated CSCC } \\
\hline & & $\begin{array}{l}\text { Control } \\
(\mathrm{n}=517)^{2}\end{array}$ & $\begin{array}{l}\text { Treated } \\
(\mathrm{n}=187)\end{array}$ & $\begin{array}{l}\text { Control } \\
(\mathrm{n}=102)\end{array}$ & $\begin{array}{l}\text { Treated } \\
(\mathrm{n}=97)\end{array}$ \\
\hline \multicolumn{6}{|l|}{ Covariates indicating change in study design } \\
\hline \multirow[t]{2}{*}{ Continuation of sampling on Staphylococcus aureus herds } & All herds (2006 and 2007) & $90.7^{*}$ & 79.1 & 87.3 & 81.4 \\
\hline & Selection of herds (2008) & 9.3 & 20.8 & 12.7 & 18.6 \\
\hline \multirow[t]{2}{*}{ Treatment:control randomization ratio for Staph. aureus } & Ratio of 1:4 (Baseline) & $79.5^{*}$ & 57.8 & 75.0 & 81.4 \\
\hline & Ratio of 1:2 (Oct 2007 - Jan 2008) & 20.5 & 42.3 & 25.0 & 18.6 \\
\hline \multirow{2}{*}{ Treatment:control randomization ratio for streptococci } & Ratio of 1:4 (2006 - June 2007) & $59.8^{*}$ & 33.2 & - & - \\
\hline & Ratio of 1:1 (July $2007-2008$ ) & 40.2 & 66.8 & - & - \\
\hline \multicolumn{6}{|l|}{ Cow-level covariates } \\
\hline \multirow[t]{3}{*}{ Lactation stage } & $0-100 \mathrm{~d}$ & 35.2 & 34.8 & $14.7^{*}$ & 39.2 \\
\hline & $101-200 \mathrm{~d}$ & 29.4 & 24.6 & 34.3 & 32.0 \\
\hline & $\geq 201 \mathrm{~d}$ & 35.4 & 40.6 & 51.0 & 28.9 \\
\hline \multirow[t]{3}{*}{ Parity } & $\overline{1}$ & 33.5 & 31.5 & 34.3 & 47.4 \\
\hline & 2 & 21.1 & 16.6 & 22.6 & 22.7 \\
\hline & $\geq 3$ & 45.4 & 51.9 & 43.1 & 22.9 \\
\hline \multirow[t]{4}{*}{ Number of quarters infected } & $\overline{1}$ & 57.1 & 55.6 & 58.8 & 45.4 \\
\hline & 2 & 32.5 & 32.6 & 31.4 & 39.2 \\
\hline & 3 & 8.1 & 9.6 & 9.8 & 15.5 \\
\hline & 4 & 2.3 & 2.1 & - & - \\
\hline \multirow[t]{2}{*}{ Season } & Housing & 62.9 & 67.9 & 58.8 & 51.5 \\
\hline & Pasture & 37.1 & 32.1 & 41.2 & 48.5 \\
\hline \multicolumn{6}{|l|}{ Quarter-level covariates } \\
\hline \multirow[t]{8}{*}{ Randomized pathogen } & Penicillin-sensitive Staph. aureus & $22.1^{*}$ & 18.2 & 33.3 & 38.1 \\
\hline & Penicillin-resistant Staph. aureus & 6.8 & 6.4 & 12.8 & 11.3 \\
\hline & CNS & 43.7 & 35.3 & 53.9 & 50.5 \\
\hline & Streptococcus uberis & 13.0 & 12.3 & - & - \\
\hline & Streptococcus dysgalactiae & 4.8 & 10.2 & - & - \\
\hline & Streptococcus agalactiae & 3.1 & 3.7 & - & - \\
\hline & Other streptococci & 4.1 & 10.7 & - & - \\
\hline & Escherichia coli & 2.5 & 3.2 & - & - \\
\hline \multirow[t]{2}{*}{ Quarter location } & Front & 44.3 & 42.3 & 42.2 & 38.1 \\
\hline & Rear & 55.7 & 57.8 & 57.8 & 61.9 \\
\hline \multirow{3}{*}{$\begin{array}{l}\text { Identification of the same pathogen in a second } \\
\text { sample pre-intervention }\end{array}$} & No pathogen present & 26.0 & 34.2 & 22.0 & 35.1 \\
\hline & Other pathogen present & 10.4 & 9.8 & 8.0 & 6.2 \\
\hline & Same pathogen present & 63.6 & 56.0 & 70.0 & 58.8 \\
\hline \multirow[t]{4}{*}{ No. of times same pathogen identified in trial 1} & 0 & - & - & 18.8 & 18.6 \\
\hline & 1 & - & - & 19.8 & 19.6 \\
\hline & 2 & - & - & 46.5 & 55.7 \\
\hline & No samples taken at $\mathrm{d} 0$ in trial 1 & - & - & 14.9 & 6.2 \\
\hline \multicolumn{6}{|l|}{${ }^{1} \mathrm{CSCC}=$ composite $\mathrm{SCC}}$. \\
\hline
\end{tabular}




\section{Treatment and Blinding}

For both the first and second elevated CSCC (trials 1 and 2 respectively), antimicrobial treatment was allocated at d 0 at the cow level; all or none of the culture-positive quarters with QSCC $\geq 100,000$ cells/ $\mathrm{mL}$ within a cow received antimicrobial treatment. Cows were treated at $\mathrm{d} 0$ after milk samples were collected. Antimicrobial treatment was performed by the farmers according to their treatment protocol, with any registered product commercially available for intramammary treatment of mastitis. Systemic treatment of SCM was not allowed during the trials.

The study was not fully blinded. Farmers knew which animals were treated and which were not. Results of the laboratory analyses of milk samples were not communicated to the farmer during the execution of the trial, except when a cow had to be treated. Then, the farmer received information about the causative pathogen, about penicillin susceptibility in the case of Staph. aureus, and about susceptibility of a specific set of antimicrobials in the case of penicillin-resistant Staph. aureus. Laboratory personnel performing bacteriological cultures and QSCC determination were blinded to treatment allocation.

\section{Sampling and Laboratory Analyses}

Single quarter milk samples were aseptically collected during regular milking before cluster attachment. After udder preparation with a cotton or paper towel by the farmer, teat ends were sanitized with cotton swabs soaked with methylated alcohol. Milk samples were aseptically collected after discarding the first squirts of milk and were stored on ice during transport to the laboratory. Samples from both trials collected at $\mathrm{d}-7$ and 21 were cultured and QSCC was determined within $24 \mathrm{~h}$. For logistical reasons, samples collected at d 0 and 28 were frozen for 1 to $30 \mathrm{~d}$ before laboratory analyses were performed.

Bacteriological culture and identification were performed according to National Mastitis Council protocols (Harmon et al., 1990). Further details of laboratory procedures were recently described by Sampimon et al. (2009). Sensitivity of penicillin-resistant Staph. aureus to a set of antimicrobials commonly used in Dutch dairy herds (a combination of nafcillin, penicillin and streptomycin, ampicillin, amoxy-clavulanic acid, cefquinome, neomycin and pirlimycin) was additionally determined using the agar diffusion test.

\section{Definitions of Outcomes}

Bacteriological cure at the quarter level, the primary outcome, was defined as absence of the isolated patho- gen at $\mathrm{d}-7$ in both samples post intervention at $\mathrm{d} 21$ and 28.

Quarter SCC, the secondary outcome, was analyzed on a continuous scale and was logarithmically converted with base $2\left(\log _{2} \mathrm{QSCC}\right)$ to normalize the data: a 1-unit decrease in $\log _{2}$ QSCC corresponds with a halving in QSCC. The statistical models for $\log _{2}$ QSCC post-intervention at d 21 were corrected for $\log _{2}$ QSCC pre-intervention $(\mathrm{d}-7)$.

Composite SCC cure, a tertiary outcome, was defined as CSCC $<250,000$ cells $/ \mathrm{mL}$ or CSCC $<150,000$ cells $/ \mathrm{mL}$ in the first milk recording post-intervention for multiparous and primiparous cows, respectively.

Milk yield $(\mathrm{kg} / \mathrm{d})$, a tertiary outcome, was evaluated as the within-cow comparison between milk yield in the "healthy" situation compared with the post-intervention situation. Milk yield at the first milk recording postintervention was therefore compared with milk yield on the last milk recording with a low CSCC before intervention.

\section{Statistical Analysis}

Only quarters with 2 bacteriological cultures postintervention (d 21 and 28) were included in all analyses (Figures 1 and 2). Crude (i.e., not corrected for other factors) bacteriological cure rates were determined for treated and control quarters in trials 1 and 2 for all pathogens. Significant differences between them were determined using $\chi^{2}$ tests per pathogen. Clinical mastitis incidence and culling rates in treated and control cows were also compared using $\chi^{2}$ tests. To compare cure of staphylococci after treatment between the first and second elevated CSCC, relative risks were calculated for treated staphylococci quarters.

Differences in distributions of covariates between treatment and control quarters that were possibly associated with therapeutic outcome were evaluated using $\chi^{2}$ tests for both trials (Table 1 ). Three covariates were related to changes in study design, 4 covariates were at the cow level (lactation stage, parity, number of quarters infected, and season) and 4 covariates were at the quarter level (quarter location, pathogen, and infectious status pre-intervention on 2 occasions).

Multivariable regression models, using PROC LOGISTIC and PROC MIXED in SAS 9.1 (SAS Institute, Cary, NC), were used to evaluate the associations between covariates and bacteriological cure, QSCC, and CSCC cure. Separate analyses were conducted for trials 1 and 2. Quarters infected with Strep. agalactiae and E. coli were excluded from all statistical models because of a low number of observations for these pathogens and because no variance was observed in treated quarters. All covariates considered to be biologically relevant 
were tested in bivariable models with treatment forced into the model to correct for treatment effects. Observations with missing values for one of the covariates were excluded from the analyses. All covariates with a $P<0.25$ in the bivariable analyses qualified for the multivariable analyses. Backward analyses, starting with the covariate with the highest $P$-value, were performed in all analyses to identify the final model in which all covariates had a significant $(P<0.05)$ contribution to the model, with the exception of CSCC cure in trial 2. For this outcome a forward approach was applied because of the low number of observations. All models were checked for confounding. Parity was forced into the models for QSCC and CSCC to correct for different thresholds in CSCC for primiparous and multiparous cows and for biological plausible relevance (Deluyker et al., 2005; Sandgren et al., 2008). Biologically plausible 2-way interactions between covariates were evaluated in the models for bacteriological cure. Subsequently, the cluster effects of cow and herd were evaluated in random effect models using xtlogit and xtreg in Stata 10.0 (Stata Corp., College Station, TX). Intra-class correlation coefficients were derived from the random effect models to determine the magnitude of clustering at the cow and herd level on the observed variance. Finally, associations between the covariates and bacteriological cure and QSCC were estimated using population-averaged models in PROC GENMOD in SAS 9.1 (SAS Institute) with clustering at the cow level to report effects at the quarter level across all cows instead of reporting effects in specific cows.

Difference in milk yield between control and treated cows and between cows with CSCC cure and with CSCC failure were evaluated using 2-sample $t$-tests. Model fit was tested in all logistic regression models with the Hosmer-Lemeshow goodness-of-fit $\chi^{2}$ test and the Pearson and deviance $\chi^{2}$ test. Model fit of linear models was observed by evaluating homoscedasticity and normality of the residuals. Model fit was determined before correcting for random cow and herd effects. All models showed a good fit for bacteriological cure and QSCC. Model fit for CSCC cure after intervention in trial 1 was moderate as indicated by a significant deviance $\chi^{2}$ test.

\section{RESULTS}

\section{Descriptive Analyses}

Data from 39 herds were used in the study. One herd with 8 quarters of 5 control cows was excluded from the study because no information on clinical mastitis and culling was available from this herd.

The flow of cows and quarters in both trials is presented in Figures 1 and 2. The percentage of random- ized cows that left trial 1 because of clinical mastitis was $6.8 \%$ for both treated and control cows. The percentage of cows with clinical mastitis that left trial 2 was $3.7 \%$ and $5.2 \%$ for treated and control cows, respectively. No treated cows were excluded from trial 1 because of culling, whereas $1.9 \%$ of the control cows were culled. In trial 2, 1.9 and $2.1 \%$ of the treated and control cows were culled, respectively. These proportions did not differ significantly between treated and control cows. Culture-positive control cows from trial 1 more often had a second elevated CSCC than did culture-negative cows: $75.9 \%[(528-127) / 528]$ and $37.8 \%$ $[(1,170-728) / 1,170]$, respectively $(P<0.0001$; Figure 2 ). Most culture-negative cows from trial 1 remained culture negative at the second elevated CSCC $(245 / 333$ $=73.6 \%$ ), whereas most culture-positive control cows from trial 1 remained culture positive at the second elevated CSCC [(202 - 37) $/ 202=81.7 \%$; Figure 2].

In both trials, CNS was the most common pathogen (Table 1). No major differences in the distribution of cow- and quarter-level covariates were found in trial 1 between treated and control quarters (Table 1). Because of a change in study design, more treated quarters had a streptococci infection compared with control quarters. In trial 2 , treated cows were more often in early lactation (Table 1).

\section{Bacteriological Cure}

Crude Cure Rates. Crude bacteriological cure rates of SCM are presented in Table 2. Treated quarters had a significantly higher cure rate than control quarters for all pathogens, with the exception of penicillin-resistant Staph. aureus in trial 2. In trial 1, bacteriological cure of treated quarters was highest for Strep. agalactiae and E. coli: all treated quarters were cured. The lowest cure rate after treatment in trial 1 was found in quarters infected with penicillin-resistant Staph. aureus. Bacteriological cure of SCM in control quarters also differed between pathogens. The highest spontaneous cure was observed in quarters infected with E. coli, and the lowest spontaneous cure was observed in quarters infected with Strep. agalactiae. In trial 2, bacteriological cure of staphylococci infections was highest for CNS and lowest for penicillin-sensitive Staph. aureus in both treated and control quarters.

Time of Treatment for Staphylococci. A trend toward a higher cure for Staph. aureus was observed when penicillin-sensitive isolates were treated earlier (Table 2). Cure was 1.50 (95\% confidence interval: 0.96-2.34) times higher after treatment at the first elevated CSCC relative to the second elevated CSCC, but was not significant $(P=0.07)$. For penicillin-resistant Staph. aureus and CNS infections, similar bacteriological cure 
rates were found after treatment at the first or second elevated CSCC.

Factors Associated with Cure in Trial 1. In Table 3 the results of the final multivariable population-averaged logistic regression model for bacteriological cure of SCM in treated and control quarters after the first elevated CSCC are shown. A higher $\log _{2}$ QSCC pre-intervention resulted in a lower cure. Bacteriological cure was also associated with the pathogen identified at d -7. Penicillin-resistant Staph. aureus had a lower odds for cure compared with CNS. Cure of other pathogens did not differ from cure of CNS. Identification of the same pathogen in the second sample pre-intervention (d 0) was associated with lower bacteriological cure in control quarters. Quarters that received treatment had a higher cure, regardless of whether no or other pathogens or the same pathogen were found at $\mathrm{d} 0$. Crude cure rates were 70.3 and $14.1 \%$ for treated and control quarters, respectively, with the same pathogen present at $\mathrm{d}-7$ and 0 . When no or other pathogens were found at d 0 , crude cure rates were 73.6 and $47.4 \%$ for treated and control quarters, respectively. No other covariates were significantly associated with bacteriological cure at the first elevated CSCC in the final model.

In a random effect model with correction for clustering at the cow level, the within-cow correlation was $0.27(P=0.03)$. The within-herd correlation was not significant $(P=0.50)$ and was not included in the final population-averaged model.

Factors Associated with Cure in Trial 2. Results from the final multivariable, population-averaged logistic regression model of risk factors related to bacteriological cure of staphylococci SCM at the second elevated CSCC are presented in Table 4 for treated and control quarters. Bacteriological cure of treated quarters was higher compared with control quarters, whereas cure was lower for penicillin-sensitive Staph. aureus infections compared with CNS infections. Bacteriological cure was higher by the end of the trial when data collection was continued on a selection of herds with a higher incidence of Staph. aureus SCM compared with the period when all herds participated. If the pathogen randomized at $\mathrm{d}-7$ in trial 2 was not identified on 1 or 2 occasions in trial 1, bacteriological cure was higher compared with the situation where the same pathogen was identified in that quarter. Bacteriological cure at the second elevated CSCC was not associated with other covariates in the final model.

The within-cow correlation was $0.52(P=0.02)$ in a random effect model with corrections for clustering at the cow level. The within-herd correlation was not significant and was not included in the final populationaveraged model.

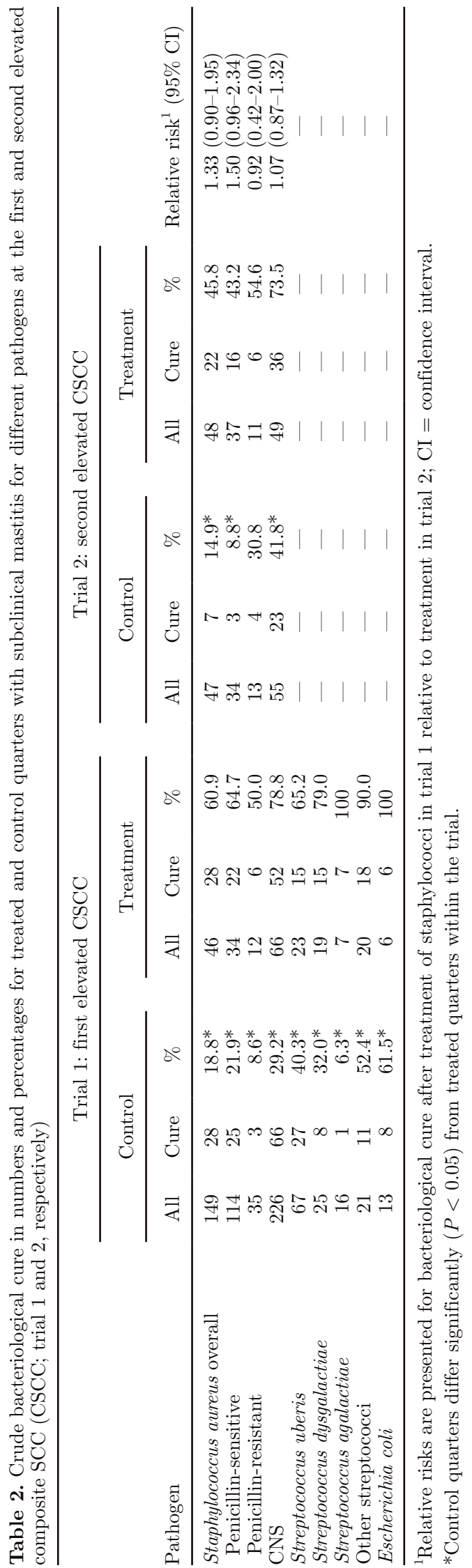


Table 3. Risk factors associated with bacteriological cure in a multivariable population-averaged logistic model with clustering at the cow level from trial 1: antimicrobial treatment of subclinical mastitis at the first elevated composite SCC

\begin{tabular}{|c|c|c|c|c|c|c|c|}
\hline \multirow[b]{2}{*}{ Variable } & \multirow[b]{2}{*}{ Category } & \multirow[b]{2}{*}{$\beta$} & \multirow[b]{2}{*}{$\mathrm{SE}$} & \multirow[b]{2}{*}{$P$-value } & \multirow[b]{2}{*}{ Odds ratio } & \multicolumn{2}{|c|}{$95 \%$ confidence interval } \\
\hline & & & & & & Lower & Upper \\
\hline Intercept & & 0.16 & 0.60 & 0.80 & - & - & - \\
\hline \multirow[t]{2}{*}{ Treatment } & Yes & 2.73 & 0.29 & 0.00 & $15.34^{1}$ & 8.61 & 27.34 \\
\hline & No & - & - & - & Ref. & - & - \\
\hline \multirow[t]{5}{*}{ Pathogen } & Penicillin-sensitive Staphylococcus aureus & -0.13 & 0.27 & 0.63 & 0.88 & 0.51 & 1.49 \\
\hline & Penicillin-resistant Staph. aureus & -1.13 & 0.43 & 0.00 & 0.32 & 0.14 & 0.75 \\
\hline & Streptococcus uberis and other streptococci & -0.45 & 0.29 & 0.12 & 0.64 & 0.36 & 1.12 \\
\hline & Streptococcus dysgalactiae & 0.39 & 0.39 & 0.31 & 1.48 & 0.70 & 3.16 \\
\hline & CNS & - & - & - & Ref. & - & - \\
\hline $\log _{2}$ QSCC pre $^{2}$ & Continuous & -0.21 & 0.07 & 0.00 & 0.81 & 0.70 & 0.93 \\
\hline \multirow{2}{*}{ Infectious status pre-intervention } & Not the same pathogen present at $\mathrm{d} 0^{3}$ & 1.76 & 0.24 & 0.00 & $5.81^{4}$ & 3.63 & 9.28 \\
\hline & Same pathogen present at $\mathrm{d} 0$ & - & - & - & Ref. & - & - \\
\hline $\begin{array}{l}\text { Interaction: treatment } \times \text { infectious } \\
\text { status pre-intervention }\end{array}$ & & -1.50 & 0.43 & 0.00 & & & \\
\hline $\begin{array}{l}\text { Effect of treatment in quarters with not } \\
\text { the same pathogen present }\end{array}$ & & & & & 3.41 & 1.81 & 6.44 \\
\hline $\begin{array}{l}\text { Effect of not having the same pathogen } \\
\text { present in treated quarters }\end{array}$ & & & & & $1.29^{5}$ & 0.65 & 2.59 \\
\hline
\end{tabular}

${ }^{1}$ The odds ratio $(\mathrm{OR})$ was calculated for the situation that the same pathogen was identified in a second sample pre-intervention (d 0$)$.

¿ $\quad{ }^{2}$ Base 2 logarithm of quarter SCC pre-intervention $(\mathrm{d}-7)$.

$\stackrel{3}{3}$ Being bacteriological culture negative or another pathogen present.

D ${ }^{4}$ The OR was calculated for control quarters.

을 ${ }^{5}$ The OR was calculated for treated quarters; the OR was not significant. 
QSCC

Mean QSCC. Geometric mean QSCC for quarters with and without bacteriological cure are shown in Table 5 for treated and control quarters from trials 1 and 2. Quarters with bacteriological cure showed a lower QSCC post-intervention compared with quarters with no bacteriological cure. Treated quarters with bacteriological cure had a lower QSCC post-intervention than control quarters with a bacteriological cure.

Factors Associated with QSCC in Trials 1 and 2. Treatment resulted in a similar decrease in $\log _{2}$ QSCC post-intervention in both trials (Table 6). Every 1-unit increase in $\log _{2}$ QSCC pre-intervention resulted in a 0.51 increase in $\log _{2}$ QSCC post-intervention in both trials. Post-intervention $\log _{2}$ QSCC was highest in quarters infected with penicillin-resistant Staph. aureus in trial 1 and in Staph. aureus quarters in trial 2. Postintervention $\log _{2}$ QSCC was lowest in CNS quarters in both trials. Cows in first, second, or third lactation had a lower $\log _{2}$ QSCC post-intervention compared with cows in higher parities in trial 1. A similar trend was observed in trial $2(P=0.48)$.

The within-cow correlations were 0.45 and 0.23 in random effect models with clustering at the cow level for trials 1 and 2, respectively. The within-herd correlations did not significantly contribute and were not included in the final population-averaged models.

\section{CSCC Cure and Milk Yield}

Crude CSCC Cure. Antimicrobial treatment of culture-positive quarters was significantly associated with decreasing CSCC in both trials. Crude CSCC cure rates were 66.0 and $41.0 \%$ in treated and control cows, respectively, in trial 1, and were 54.9 and $22.6 \%$, respectively, in trial $2(P<0.0001$ for both trials).

Factors Associated with CSCC Cure in Trial 1 and 2. Treatment was also associated with higher CSCC cure in multivariable models for both trials (Tables 7 and 8). A higher CSCC pre-intervention was associated with lower CSCC cure rate in both trials. In trial 1, cows with only CNS identified pre-intervention had higher CSCC cure rate than cows infected with at least 1 major pathogen in one of their quarters. In both trials, cows that were culture positive in all high QSCC quarters (QSCC $\geq 100,000$ cells $/ \mathrm{mL}$ at $\mathrm{d}-7$ ) had higher CSCC cure than cows with one or more high QSCC quarters that were culture negative (and were not treated); this finding was not significant in trial 2 $(P=0.27)$.

The random herd effects were not significant in both trials and were excluded from the final models.

Milk Yield. Milk yield decreased on average 3.6 $\mathrm{kg} / \mathrm{d}(\mathrm{SE}=0.6)$ and $2.7 \mathrm{~kg} / \mathrm{d}(\mathrm{SE}=0.4)$ in treated 
Table 5. Geometric mean of quarter SCC $\left(\times 10^{3}\right.$ cells $\left./ \mathrm{mL}\right)$ pre- $(\mathrm{d}-7)$ and post- $(\mathrm{d} 21)$ intervention for quarters with bacteriological cure and failure for treated and control quarters with subclinical mastitis at the first and second elevated composite SCC (CSCC; trial 1 and 2, respectively) ${ }^{1}$

\begin{tabular}{|c|c|c|c|c|c|c|c|c|}
\hline \multirow[b]{3}{*}{ Day } & \multicolumn{4}{|c|}{ Trial 1: first elevated CSCC } & \multicolumn{4}{|c|}{ Trial 2: second elevated CSCC } \\
\hline & \multicolumn{2}{|c|}{ Control } & \multicolumn{2}{|c|}{ Treatment } & \multicolumn{2}{|c|}{ Control } & \multicolumn{2}{|c|}{ Treatment } \\
\hline & Cure & Failure & Cure & Failure & Cure & Failure & Cure & Failure \\
\hline-7 & $397^{\mathrm{a}}$ & $514^{\mathrm{a}}$ & $464^{\mathrm{a}}$ & $1,042^{\mathrm{a}}$ & $331^{\mathrm{a}}$ & $679^{\mathrm{a}}$ & $449^{\mathrm{a}}$ & $668^{\mathrm{a}}$ \\
\hline 21 & $260^{\mathrm{b} *}$ & $482^{\mathrm{a}}$ & $84^{\mathrm{b}}$ & $430^{\mathrm{b}}$ & $351^{\text {a* }}$ & $709^{\mathrm{a}}$ & $91^{\mathrm{b}}$ & $461^{\mathrm{a}}$ \\
\hline
\end{tabular}

${ }^{\mathrm{a}, \mathrm{b}}$ Values within the same column with different superscripts differ significantly $(P<0.05)$.

${ }^{1}$ Trial 1 included staphylococci and non-agalactiae streptococci, whereas trial 2 included only staphylococci.

*Cured control quarters had a significantly higher quarter SCC post-intervention than cured treated quarters within the trial.

and control cows, respectively, in trial 1 and did not differ between them $(P=0.22)$. For trial 2 , milk yield was on average $3.0 \mathrm{~kg} / \mathrm{d}(\mathrm{SE}=1.42)$ and $4.3 \mathrm{~kg} / \mathrm{d}(\mathrm{SE}$ $=0.6)$ lower in treated and control cows, respectively, and did not differ them $(P=0.39)$. Milk yield in cows with CSCC cure was not different from cows with a failure of CSCC cure in both trials.

\section{DISCUSSION}

The overall aim of this study was to evaluate therapeutic success after antimicrobial treatment of RASCM using CSCC measurements and bacteriological culturing as a practical tool. With that aim, cows with a single culture-positive sample at the first or second elevated CSCC after 2 consecutive milk CSCC recordings below the threshold were defined to have RASCM. First, the criterion of 2 consecutive CSCC measurements below the thresholds was set to increase the probability of identifying new SCM. Duration of SCM in the trial was not longer than $38(28+10)$ d at the moment of identification $(\mathrm{d}-7)$ and no longer than $45(28+10+7) \mathrm{d}$ at the moment of antimicrobial treatment ( $\mathrm{d} 0$ ) because herds with a 4-weekly milk recording were selected and cows were sampled within $10 \mathrm{~d}$ after the milk recording. However, infections may have been present longer at the quarter level in cows with a low CSCC because of the low sensitivity of CSCC thresholds for identifying new infections at the quarter level (Dohoo and Leslie, 1991). Second, a quarter was defined to have SCM when a single sample was culture-positive pre-intervention, where consecutive samples are advocated in field studies to increase sensitivity (Barkema et al., 2006). However, in dairy practice, often only 1 quarter milk sample is taken to diagnose SCM for practical reasons and because of the associated costs. Consequently, enrollment in our study was based on just 1 culture-positive sample, combined with QSCC $\geq 100,000$ cells/mL. Nevertheless,

Table 6. Risk factors associated with quarter SCC at d 21 (on a base 2 logarithm scale) in multivariable population-averaged linear models with clustering at the cow level from trial 1 and 2: antimicrobial treatment of subclinical mastitis at the first and second elevated composite SCC $(\text { CSCC })^{1}$

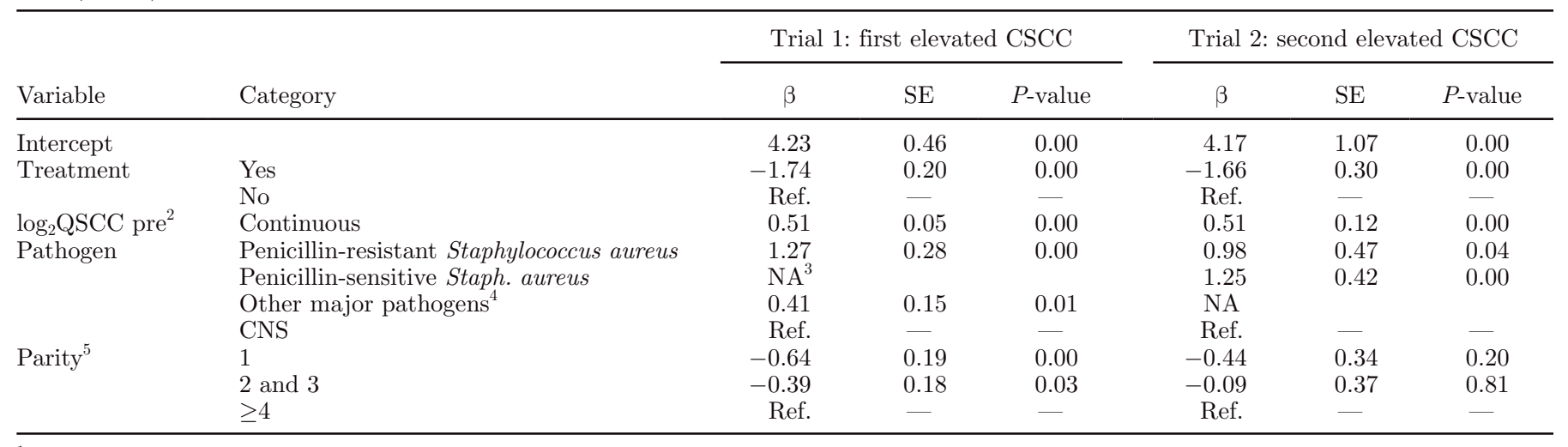

${ }^{1}$ Trial 1 included staphylococci and non-agalactiae streptococci, whereas trial 2 included staphylococci only.

${ }^{2}$ Base 2 logarithm of quarter somatic cell count pre-intervention $(\mathrm{d}-7)$.

${ }^{3}$ Not applicable.

${ }^{4}$ Penicillin-resistant Staph. aureus, Streptococcus uberis, Streptococcus dysgalactiae, other streptococci.

${ }^{5}$ Parity was not significant $(P=0.48)$ in trial 2 but was forced into the model to correct for different CSCC thresholds at the cow level for enrollment for primiparous and multiparous cows. 
Table 7. Risk factors associated with cure of composite somatic cell count $(\mathrm{CSCC})^{1}$ in a multivariable logistic model from trial 1: antimicrobial treatment of subclinical mastitis at the first elevated CSCC

\begin{tabular}{|c|c|c|c|c|c|c|c|}
\hline \multirow[b]{2}{*}{ Variable } & \multirow[b]{2}{*}{ Category } & \multirow[b]{2}{*}{$\beta$} & \multirow[b]{2}{*}{$\mathrm{SE}$} & \multirow[b]{2}{*}{$P$-value } & \multirow[b]{2}{*}{ Odds ratio } & \multicolumn{2}{|c|}{$95 \% \mathrm{CI}$} \\
\hline & & & & & & Lower & Upper \\
\hline Treatment & No & - & - & - & Ref. & - & - \\
\hline \multirow[t]{2}{*}{ Pathogen } & Only CNS & 0.57 & 0.20 & 0.00 & 1.76 & 1.19 & 2.61 \\
\hline & Any major pathogen in 1 or more quarters & - & - & - & Ref. & - & - \\
\hline pre-intervention $^{3}$ & Some quarters bacteriological culture negative & - & - & - & Ref. & - & - \\
\hline \multirow{2}{*}{ Parity $^{4}$} & 1 & 0.20 & 0.21 & 0.35 & 0.82 & 0.54 & 1.24 \\
\hline & $\geq 2$ & - & - & - & - & - & - \\
\hline
\end{tabular}

\footnotetext{
${ }^{1} \mathrm{~A}$ cow was defined to be cured if $\mathrm{CSCC}$ was $<250,000$ cells $/ \mathrm{mL}$ for multiparous cows and $<150,000$ for primiparous cows at the first milk recording post-intervention.

${ }^{2}$ Base 2 logarithm of CSCC pre-intervention.

${ }^{3}$ Determined in quarters with a quarter somatic cell count $\geq 100,000$ cells $/ \mathrm{mL}$ at $\mathrm{d}-7$.

${ }^{4}$ Parity was not significant $(P=0.35)$ but was forced into the model to correct for different CSCC thresholds at enrollment for primiparous and multiparous cows.
}

a second sample was taken pre-intervention. Spontaneous bacteriological cure in control quarters with 2 culture-positive consecutive samples pre-intervention was lower than in quarters with 1 culture-positive and 1 culture-negative sample. However, cure after treatment was the same for quarters with 1 or 2 cultures positive (Table 3). Therefore, the method applied in this study to identify quarter-level RASCM by monthly changes in CSCC and a single culture-positive sample with QSCC >100,000 cells $\mathrm{m} / \mathrm{L}$ has diagnostic value in dairy practice for treatment decisions.

Bacteriological cure rates determined in trial 1 were comparable to cure rates observed in other studies, with the exception of the cure rate for Staph. aureus, which was higher than expected. Early treatment of streptococci SCM did not seem to improve cure relative to that reported by others (McDougall, 1998; Wilson et al., 1999; St. Rose et al., 2003; Oliver et al., 2004; Salat et al., 2008). For CNS, the most frequently identified pathogen in the Netherlands (Table 1; Sampimon et al., 2009), crude cure rates of 79 and $74 \%$ were found in treated quarters in trial 1 and 2, respectively; these rates were comparable to other studies with more chronic cases (McDougall, 1998; Wilson et al., 1999; Oliver et al., 2004; Salat et al., 2008). Early treatment of CNS SCM did not reveal higher cure rates. Cure of penicillin-resistant Staph. aureus after treatment with non- $\beta$-lactam antimicrobials was higher than the cure rate of $24 \%$ found earlier in the Netherlands (Sol et al., 1997), probably a result of the more chronic nature of infections in the earlier study. The number of penicillinresistant Staph. aureus infections was too low to evaluate treatment efficacy in trial 2 , but treated quarters in trial 1 had a better cure rate than control quarters. Treatment of penicillin-sensitive Staph. aureus SCM af- ter the first elevated CSCC resulted in a nonsignificant but numerically higher crude cure rate $(65 \%)$ compared with treatment after the second elevated CSCC (43\%). Others observed crude cure rates from $7 \%$ (Oliver et al., 2004) to $49 \%$ (Wilson et al., 1999), but cure varies greatly with different cow characteristics (Sol et al., 1997; Deluyker et al., 2005; Sandgren et al., 2008). Interestingly, cure of penicillin-sensitive Staph. aureus in control quarters was also higher at the first elevated CSCC (22\%) compared with spontaneous cure after the second elevated CSCC (9\%). Cure rates previously found in control quarters ranged from $0 \%$ (Oliver et al., 2004) to $43 \%$ (Wilson et al., 1999), but were mostly below 10\% (Deluyker et al., 2005; Salat et al., 2008; Sandgren et al., 2008). Most studies did not differentiate between $\beta$-lactamase-positive and $\beta$-lactamase-negative isolates, whereas $\beta$-lactamase production by Staph. aureus decreases cure rates (Sol et al., 1997; Barkema et al., 2006). Our cure rates, therefore, may not be fully comparable to those found by others.

Treatment protocols (i.e., duration of treatment or the antimicrobial compound being used) did not differ between the trials (data not shown). We can therefore only speculate on possible explanations for the tendency in decreased cure rates for penicillin-sensitive Staph. aureus infections at the second elevated CSCC, where no decreasing effect was observed for penicillin-resistant Staph. aureus strains. It is likely that more chronic infections cause more severe tissue damage (Barkema et al., 2006). Additionally, the formation of biofilm by the pathogen in the udder may be one of the reasons (Melchior et al., 2006). Moreover, certain bovine Staph. aureus strains can be internalized by mammary epithelial cells (Buzzola et al., 2007). All possible explanations reduce the accessibility of cows' leucocytes and 
antimicrobials to the infection site but do not explain the difference found between penicillin-sensitive and penicillin-resistant Staph. aureus strains. This is probably caused by different genotypes (Barkema et al., 2006), but further studies are needed to elucidate their role in interference with treatment.

Time of treatment for staphylococci was evaluated in this study using relative risk calculations from $2 \times$ 2 tables. Mixed models with repeated measures could have been used to evaluate both treatment moments for staphylococci in 1 data set. This method was applied but gave instable results, because of the unbalanced study design chosen. Inclusion criteria differed between both trials. In trial 2, untreated staphylococci culture-positive cows from trial 1 with a second elevated CSCC were eligible for enrollment, whereas in trial 1 all culture-positive cows enrolled, resulting in repeated observations for quarters in trial 2 only. The current study can be used as the basis for a power calculation to design a trial to evaluate the difference in cure after antimicrobial treatment of Staph. aureus SCM between the first or second elevated CSCC.

Farmers were free to use any commercially available antimicrobial product for intramammary treatment of mastitis in both trials according to their treatment protocol, to increase compliance and to stay as close as possible to Dutch dairy practice. Therapeutic effects of different treatment regimens have been extensively reviewed (Barkema et al., 2006). Nevertheless, the different therapies were evaluated for differences in bacteriological cure for both trials (results not shown). A model with duration of treatment had the best model fit in the univariable analyses for trial 1 to affect cure rates and was described previously (Oliver et al., 2004; Deluyker et al., 2005). In trial 2, products with lincosamides and aminoglycosides as one of their active compounds gave a higher cure rate for staphylococci compared with products containing penicillin or penicillin-derived antimicrobials as their active compound. However, therapies differed more between herds than within herds, with some herds in trial 2 contributing more to the data than others. Additionally, not many differences between antimicrobial compounds have been observed before (Wilson et al., 1999; Barkema et al., 2006). Thus, it remains unknown whether the differences found in our study are due to the active compound or to differences between herds.

Treatment, pathogen, and penicillin susceptibility of Staph. aureus in both trials and QSCC in trial 1 affected cure rates as expected (Sol et al., 1997; Oliver et al., 2004; Deluyker et al., 2005). Control quarters in trial 1 showed a higher bacteriological cure after a single culture-positive isolation pre-intervention, but no differences in cure rates were observed in treated quarters 
with 1 or 2 consecutive culture-positive samples. Possible explanations for a single isolation from 2 samples are the test characteristics of bacteriological culturing (Gonano and Winter, 2008), low shedding of bacteria (Sears et al., 1990), false-positive samples caused by contamination or teat canal flora, or spontaneous cure. In trial 2, a better cure rate was observed if at the first elevated CSCC the same pathogens were not identified or no sample was taken at $d 0$ in trial 1 . These quarters were probably not infected at that time as indicated by 2 culture-negative samples or a low QSCC at $\mathrm{d}-7$ in trial 1 and are therefore reflecting a newer SCM at the second elevated CSCC resulting in higher cure rates after treatment (Sol et al., 1994, 1997; Dingwell et al., 2003). The prolonged data collection on approximately half of the herds to reach the required sample size for Staph. aureus was associated with a higher cure rate in trial 2. These herds were selected for prolonged data collection based on a high incidence of subclinical Staph. aureus SCM to reach the required sample sizes for this pathogen. No covariates were found to explain the better cure rate after treatment in those herds.

Previously identified cow factors associated with bacteriological cure and SCC post-intervention, such as lactation stage, quarter location, parity, and number of quarters infected (Sol et al., 1997; Deluyker et al., 2005) were not associated with therapeutic success of RASCM in our study. This was, to a lesser extent, also observed by Salat et al. (2008), where only the number of infected quarters was related to bacteriological cure. Their inclusion criteria were comparable to ours for trial 2. The effect of parity on QSCC and CSCC cure was the only cow factor affecting therapeutic success in our study, most likely caused by different CSCC selection criteria at the moment of enrollment in the study. The factors observed in other studies may therefore be more related to chronicity of infection, where that effect was minimized in our study because of selection. Severity and duration of infection, as reflected by QSCC and multiple consecutive culture-positive samples, seem to be the only cow factors influencing cure. This stresses the importance of early identification of new SCM cases for a successful treatment as was investigated in this study.

As in other studies, antimicrobial treatment of SCM decreased QSCC and gave a higher probability of CSCC cure in both trials (McDougall, 1998; St. Rose et al., 2003; Deluyker et al., 2005; Beggs and Wraight, 2006; Salat et al., 2008; Sandgren et al., 2008). Also, differences found between pathogens in $\log _{2}$ QSCC and CSCC cure were related to differences in bacteriological cure rates. The reduced CSCC cure was somewhat less expected when some of the quarters with a high QSCC $(>100,000$ cells $/ \mathrm{mL}$ ) were culture-negative but can be explained by the sensitivity of bacteriological culturing as these quarters were probably infected but not diagnosed as such. These quarters were left untreated, resulting in a higher QSCC and thus a lower CSCC cure.

This study showed that early diagnosis and treatment of Staph. aureus SCM resulted in increased cure rates and should be advocated in dairy practice to improve cure rates. However, we do not promote treating every cow or quarter with an elevated SCC. Bacteriological cultures have to be taken to identify SCM per quarter because only $44 \%$ of the cows with a first elevated CSCC were bacteriological culture positive. This is especially important in the context of the current focus to reduce antimicrobial usage in animal production and its possible relationship with antimicrobial resistance (Hendriksen et al., 2008). Prudent use of antimicrobials at the first elevated CSCC is possible when cows and quarters are positively confirmed by bacteriological culture or other diagnostic techniques.

This study evaluated only short-term therapeutic effects of antimicrobial treatment of SCM during lactation. Treatment of RASCM did not seem to affect clinical mastitis occurrence, milk yield, or culling rates during the first $28 \mathrm{~d}$ post-intervention. Whether antimicrobial treatment of RASCM affects clinical mastitis and culling in the long-term needs further study. Additionally, treatment may only be economically feasible in herds with a decreased transmission of pathogens within the herd (Barlow et al., 2009). Further economic evaluation is therefore needed and should also take the costs of diagnosing RASCM into account.

\section{CONCLUSIONS}

Antimicrobial treatment of SCM after the first and second elevated CSCC resulted in increased bacteriological cure rates, lower QSCC, and higher probabilities of CSCC cure compared with control cows and quarters. Treatment of streptococci at the first elevated CSCC showed good but not better cure rates relative to what has previously been observed. The moment of antimicrobial treatment did not seem to influence cure rates for CNS. For Staph. aureus infections, a tendency toward a higher cure rate was observed at the first elevated CSCC compared with the second elevated CSCC. Treatment of Staph. aureus SCM is therefore relatively more effective in an early state compared with other pathogens. Cow-level factors previously known to reduce bacteriological cure did not seem to be associated with cure of RASCM and might be more related to chronicity of infection. Diagnosing RASCM by changes in CSCC and a single culture-positive milk sample with a QSCC $>100,000$ cells $/ \mathrm{mL}$ is a useful and practical tool for early treatment of SCM. 


\section{ACKNOWLEDGMENTS}

This study is part of the 5-yr mastitis program of the Dutch Udder Health Centre and was financially supported by the Dutch Dairy Board. The authors thank the farmers for participating in the study, field personnel for collecting milk samples, and personnel from the bacteriology department of GD laboratory for performing all laboratory analyses. The comments of Ynte Hein Schukken (Cornell University, Ithaca, NY) and Otlis Sampimon (GD Animal Health Service, Deventer, the Netherlands) on the set up and execution of the trial and the comments of Ruth Zadoks (Moredun Research Institute, Penicuik, UK) on an earlier version of the manuscript are highly appreciated. Vera Eerland (GD Animal Health Service) is gratefully acknowledged for coordinating a large part of the field work.

\section{REFERENCES}

Barkema, H. W., Y. H. Schukken, and R. N. Zadoks. 2006. Invited review: The role of cow, pathogen, and treatment regimen in the therapeutic success of bovine Staphylococcus aureus mastitis. J. Dairy Sci. 89:1877-1895.

Barlow, J. W., L. J. White, R. N. Zadoks, and Y. H. Schukken. 2009. A mathematical model demonstrating indirect and overall effects of lactation therapy targeting subclinical mastitis in dairy herds. Prev. Vet. Med. 90:31-42.

Beggs, D. S., and M. D. Wraight. 2006. Pilot study-Parenteral treatment of recently acquired subclinical mastitis during lactation. Aust. Vet. J. 84:50-52.

Buzzola, F. R., L. P. Alvarez, L. P. N. Tuchscherr, M. S. Barbagelata, S. M. Lattar, L. Calvinho, and D. O. Sordelli. 2007. Differential abilities of capsulated and noncapsulated Staphylococcus aureus isolates from diverse agr groups to invade mammary epithelial cells. Infect. Immun. 75:886-891.

Deluyker, H. A., S. N. Van Oye, and J. F. Boucher. 2005. Factors affecting cure and somatic cell count after pirlimycin treatment of subclinical mastitis in lactating cows. J. Dairy Sci. 88:604-614.

Dingwell, R. T., K. E. Leslie, T. F. Duffield, Y. H. Schukken, L. DesCoteaux, G. P. Keefe, D. F. Kelton, K. D. Lissemore, W. Shewfelt, P. Dick, and R. Bagg. 2003. Efficacy of intramammary tilmicosin and risk factors for cure of Staphylococcus aureus infection in the dry period. J. Dairy Sci. 86:159-168.

Dohoo, I. R., and K. E. Leslie. 1991. Evaluation of changes in somatic cell counts as indicators of new intramammary infections. Prev. Vet. Med. 10:225-237.

Gonano, M., and P. Winter. 2008. Phenotypic and molecular identification of Streptococcus species isolated from milk of intramammary infected dairy cows in Austria. Pages 191-198 in Mastitis Control: From Science to Practice. Proc. Int. Conf. T.J.G.M. Lam, ed. Wageningen Academic Publishers, The Hague, the Netherlands.

Harmon, R. J., R. J. Eberhart, D. E. Jasper, B. E. Langlois, and R. A. Wilson. 1990. Microbiological procedures for the diagnosis of udder infection. 3rd ed. National Mastitis Council Inc., Arlington, VA.

Hendriksen, R. S., D. J. Mevius, A. Schroeter, C. Teale, D. Meunier, P. Butaye, A. Franco, A. Utinane, A. Amado, M. Moreno, C. Greko, K. Stärk, C. Berghold, A. L. Myllyniemi, D. Wasyl, M. Sunde, and F. M. Aarestrup. 2008. Prevalence of antimicrobial resistance among bacterial pathogens isolated from cattle in different European countries: 2002-2004. Acta Vet. Scand. 50:28.

Lam, T. J. G. M., M. C. M. de Jong, Y. H. Schukken, and A. Brand. 1996. Mathematical modeling to estimate efficacy of postmilking teat disinfection in split-udder trials of dairy cows. J. Dairy Sci. 79:62-70.
McDougall, S. 1998. Efficacy of two antibiotic treatments in curing clinical and subclinical mastitis in lactating dairy cows. N. Z. Vet. J. $46: 226-232$.

Melchior, M. B., H. Vaarkamp, and J. Fink-Gremmels. 2006. Biofilms: A role in recurrent mastitis infections? Vet. J. 171:398-407.

Milner, P., K. L. Page, and J. E. Hillerton. 1997. The effects of early antibiotic treatment following diagnosis of mastitis detected by a change in the electrical conductivity of milk. J. Dairy Sci. 80:859 863.

Oliver, S. P., B. E. Gillespie, S. J. Headrick, H. Moorehead, P. Lunn, H. H. Dowlen, D. L. Johnson, K. C. Lamar, S. T. Chester, and W. M. Moseley. 2004. Efficacy of extended ceftiofur intramammary therapy for treatment of subclinical mastitis in lactating dairy cows. J. Dairy Sci. 87:2393-2400.

Owens, W. E., C. H. Ray, J. L. Watts, and R. J. Yancey. 1997. Comparison of success of antibiotic therapy during lactation and results of antimicrobial susceptibility tests for bovine mastitis. J. Dairy Sci. 80:313-317.

Reksen, O., L. Sølverød, A. J. Branscum, and O. Østerås. 2006. Relationships between milk culture results and treatment for clinical mastitis or culling in Norwegian dairy cattle. J. Dairy Sci. 89:2928-2937.

Reksen, O., L. Sølverød, and O. Østerås. 2007. Relationships between milk culture results and milk yield in Norwegian dairy dattle. J. Dairy Sci. 90:4670-4678.

Salat, O., F. Sérieys, B. Poutrel, L. Durel, and L. Goby. 2008. Systemic treatment of subclinical mastitis in lactating cows with penethamate hydriodide. J. Dairy Sci. 91:632-640.

Sampimon, O., H. W. Barkema, I. Berends, J. Sol, and T. Lam. 2009. Prevalence of intramammary infection in Dutch dairy herds. J. Dairy Res. 76:129-136.

Sandgren, C. H., K. Persson Waller, and U. Emanuelson. 2008. Therapeutic effects of systematic or intramammary antimicrobial treatment of bovine subclinical mastitis during lactation. Vet. J. 175:108-177.

Schukken, Y. H., D. J. Wilson, F. Welcome, L. Garrison-Tikofsky, and R. N. Gonzalez. 2003. Monitoring udder health and milk quality using somatic cell counts. Vet. Res. 34:579-596.

Sears, P. M., B. S. Smith, P. B. English, P. S. Herer, and R. N. Gonzalez. 1990. Shedding pattern of Staphylococcus aureus from bovine intramammary infections. J. Dairy Sci. 73:2785-2789.

Sol, J., O. C. Sampimon, J. J. Snoep, and Y. H. Schukken. 1994. Factors associated with bacteriological cure after dry cow treatment of subclinical staphylococcal mastitis with antibiotics. J. Dairy Sci. $77: 75-79$.

Sol, J., O. C. Sampimon, J. J. Snoep, and Y. H. Schukken. 1997. Factors associated with bacteriological cure during lactation after therapy for subclinical mastitis caused by Staphylococcus aureus. J. Dairy Sci. 80:2803-2808.

St. Rose, S. G., J. M. Swinkels, W. D. J. Kremer, C. L. J. J. Kruitwagen, and R. N. Zadoks. 2003. Effect of penethamate hydriodide treatment on bacteriological cure, somatic cell count and milk production of cows and quarters with chronic subclinical Streptococcus uberis or Streptococcus dysgalactiae infection. J. Dairy Res. 70:387-394.

Steeneveld, W., J. Swinkels, and H. Hogeveen. 2007. Stochastic modelling to assess economic effects of treatment of chronic subclinical mastitis caused by Streptococcus uberis. J. Dairy Res. 74:459-467.

Swinkels, J. M., H. Hogeveen, and R. N. Zadoks. 2005. A partial budget model to estimate economic benefits of lactational treatment of subclinical Staphylococcus aureus mastitis. J. Dairy Sci. 88:42734287.

Wilson, D. J., R. N. Gonzalez, K. L. Case, L. L. Garrison, and Y. T. Gröhn. 1999. Comparison of seven antibiotic treatments with no treatment for bacteriological efficacy against bovine mastitis pathogens. J. Dairy Sci. 82:1664-1670.

Zadoks, R. N., H. G. Allore, H. W. Barkema, O. C. Sampimon, Y. T. Gröhn, and Y. H. Schukken. 2001. Analysis of an outbreak of Streptococcus uberis mastitis. J. Dairy Sci. 84:590-599. 